Case Report

\title{
Familial colloid cyst of the third ventricle in monozygotic twins
}

\section{Introduction}

Colloid cysts are slow-growing non-neoplastic true epithelium lined cysts of the central neuraxis, usually arising in the third ventricle. ${ }^{1}$ The first description was published in 1858 by Wallmann ${ }^{2}$ as an autopsy finding. They constitute $0.5-2 \%$ of all intracranial tumors and comprise $55 \%$ of the third ventricle's lesions. ${ }^{3}$ Colloid cysts are and can be found in patients of any age, with a peak between the second and the fourth decades, and no differences in distribution according to sex. ${ }^{4}$ The wall usually consists of a collagenous connective tissue stroma lined by single layer of columnar epithelium. ${ }^{4}$

Colloid cysts are often found incidentally, but when symptomatic, they present usually with signs and symptoms of acute or chronic obstructive hydrocephalus, by occlusion of the foramen of Monro. ${ }^{5}$ Sudden death, as consequence of untreated hydrocephalus and raised intracranial pressure, is well recognized in patients with colloid cyst. ${ }^{4-6}$ The treatment is surgical, endoscopic or microsurgical. ${ }^{4}$

A study of 155 patients with newly diagnosed colloid cysts showed four factors associated with cyst related symptoms: 1) younger patient age (44 years versus 57 years), 2) cyst size (13 mm versus $8 \mathrm{~mm}$ ), 3 ) ventricular dilation ( $83 \%$ versus $31 \%)$,and 4 ) increased signal on T2-weighted magnetic resonance images (44\% versus $8 \%) .{ }^{1}$ More than half of cases were discovered incidentally. In five patients with incidental cysts (8.8\%) an enlargement of the cyst was documented and a surgical procedure was done. Nearly half of symptomatic patients present hydrocephalus, more than $10 \%$ present an acute symptom, and $1 \%$ of patients decease due to obstructive hydrocephalus and herniation. ${ }^{1}$

Some familial cases were previously reported, including monozygotic and dizygotic twins. Most of the familial colloid cysts were treated operatively, although few cases were treated conservatively, with regular radiological follow up. ${ }^{7-9}$ To our knowledge, only 4 pairs of twins with colloid cyst have been previously reported in the literature, three of which are monozygotic and the other one is dizygotic. ${ }^{10-13}$

In this report, we present the fourth monozygotic twins with this potentially life-threatening pathology. The two brothers were operated four years apart after presenting with different clinical scenarios.

\section{Clinical presentation}

\section{Brother A}

The 31-years-old (Figure 1) patient was admitted to a hospital in another country in 2012 following a generalized tonic-clonic seizure. After first stabilization the patient was neurologically intact without any signs and symptoms of increased intracranial pressure. A prophylactic antiepileptic therapy with levitracetam was initiated. An MRI was done and showed an isointense in T1 and T2WI and a hyperintense mass in the fluid attenuated inversion recovery sequence suggesting the diagnosis of a colloidal cyst of the third ventricle causing the pathognomonic obstructive hydrocephalus involving only the lateral ventricles (Figures 2-5).
Volume 6 Issue $6-2017$

\author{
Mohsen Yaish,' Lehel Török,' Bruno Zanotti, ${ }^{2}$ \\ Alex Alfieri ${ }^{1,3}$ \\ 'Department of Neurosurgery and Spinal Surgery, Brandenburg \\ Medical School, Campus Neuruppin, Germany \\ ${ }^{2}$ Department of Neurosurgery, University Hospital of Udine, \\ Italy \\ ${ }^{3}$ Department of Neurosurgery, Kantonsspital Winterthur, \\ Switzerland
}

Correspondence: Alex Alfieri, Chairman, Neurological and Spinal Surgery, Brandenburg Medical School Campus Neuruppin, Fehrbelliner Straße 38 D-16816 Neuruppin, Germany, Tel +49 (0)3391 39-47600, Fax +49 (0)3391 39-47609, Email neurochirurgie@ruppiner-kliniken.de

Received: February 02, 2017 | Published: May 22, 2017

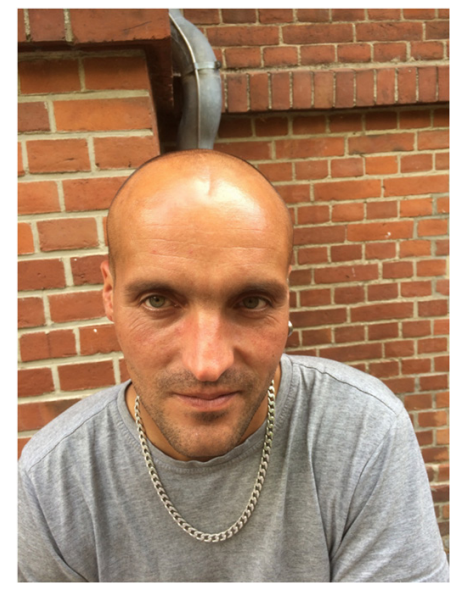

Figure I Brother A, year 2016. The microsurgical removal of the colloid cyst was performed in year 2013. Permission kindly granted by the patient.

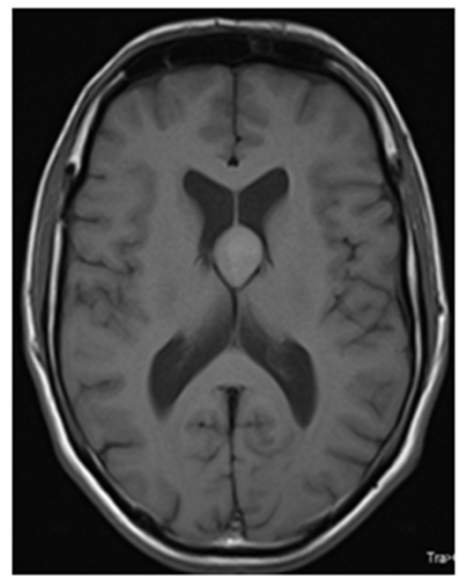

Figure 2 MRI TI (Brother A): $18 \times 22 \mathrm{~mm}$ well circumscribed colloid cyst in the $3 r d$ ventricle extending in the lateral ventricles. 


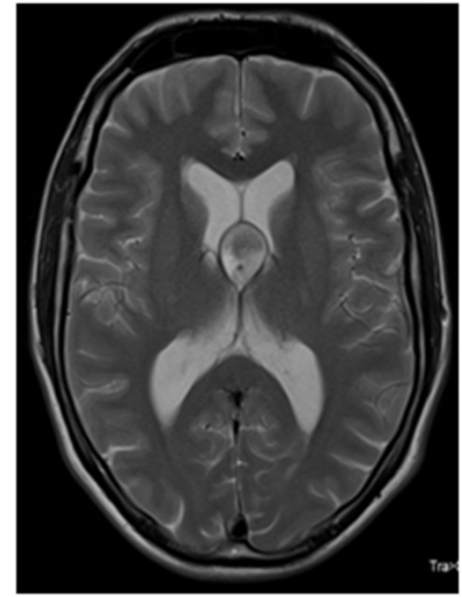

Figure 3 MRIT2 transverse (Brother A).

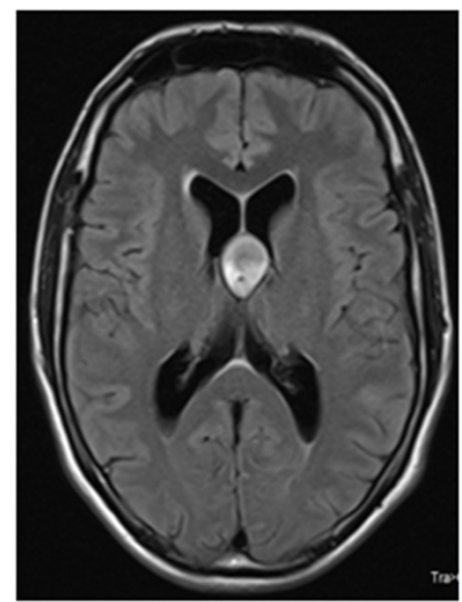

Figure $4 \mathrm{MRI}$ (Brother A) fluid attenuated inversion recovery sequence trasverse.

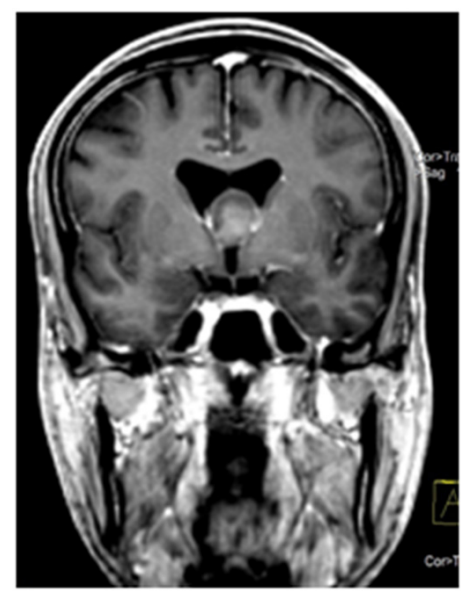

Figure 5 MRI (Brother A) Coronal view TI.

The cyst was removed through a right frontal craniotomy through a transcortical transventricular approach. Postoperatively, the patient was discharged after two weeks with an intact neurological status. Because the patient was in another country, no further investigations were done.

\section{Brother B}

In 2016, while working as a carpenter, monozygotic brother B (Figure 6) suddenly fell into a generalized tonic-clonic seizure.
When the emergency doctor arrived at the workplace the patient presented a Glasgow Coma Score of 4 (E1, V1, M2), wide bilateral pupils without response to the light. The patients was intubated and conducted to the emergency room of our hospital. The neurologic status offered no brainstem reactions, wide pupils bilateral without response to the light, no motor response. Funduscopic examination revealed acute papilledema. A non-contrast CT of the brain showed a well-defined 30x33 mm hyperdense lesion in the third ventricle with massive obstructive hydrocephalus of the lateral ventricles (Figure 7), with the classical appearance of a colloid cyst. In further questioning, the family reported that the patient suffered a history of headache with nausea and vomiting over the last week. Due to the wrong neurological status of the patient an MRI was omitted preoperatively and the patient was urgently microsurgically treated. Under general anesthesia, a frontal craniotomy was made in the right side in supine position and through a transcortical-transventricular approach the cyst was microsurgical removed with a temporary placement of a closed external ventricular drain (EVD) to prevent the possible complication of hydrocephalus. Postoperatively, the patient was early extubated and he was neurologically intact. The pupils were bilateral isochoric, miotic and well responsible to the light. During the first three days postoperatively there was not need to open the EVD, and consequentially it was removed. The histopathological analysis confirmed the diagnosis of colloid cyst, which was positive for CK AE1/AE3 and EMA, negative for CDX-2, TTF-1 and S-100. A 5 days follow up CT showed a mild hydrocephalus (Figure 8). The patient was discharged in the second postoperative week without neurological deficit. A neuropsychological evaluation after six months revealed mild attention impairments. The patient went back to work after six months. The rest of the family underwent prophylactic screening without other pathological signs.

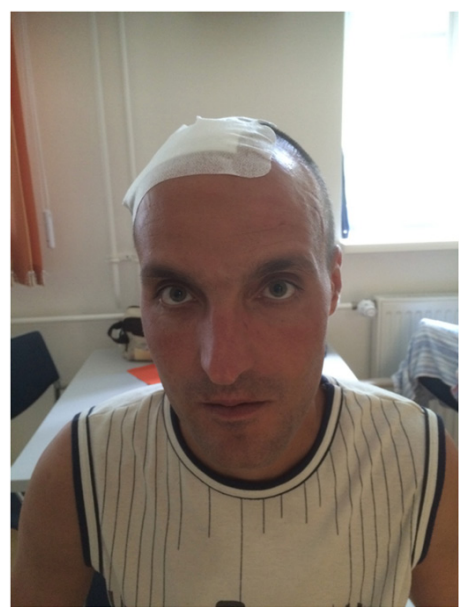

Figure 6 Brother B, 2016. Three days after microsurgical removal of the colloid cyst. No neurological impairments were registered. Permission kindly granted by the patient.

\section{Discussion}

Familial colloid cysts are extremely rare; only around 30 cases were mentioned in the literature. ${ }^{7-13}$ With the presented cases there will be until now 5 registered pairs of twins with colloid cysts with a total of four monozygotic twins and one dizygotic twin. The autosomal dominant inheritance was previously postulated. ${ }^{9}$ These findings suggest an increase in the incidence of colloid cyst in twins as compared to the general population. Accordingly the performing of a magnetic resonance imaging in both twins is advisable, if one of them was proved to have a colloid cyst. 


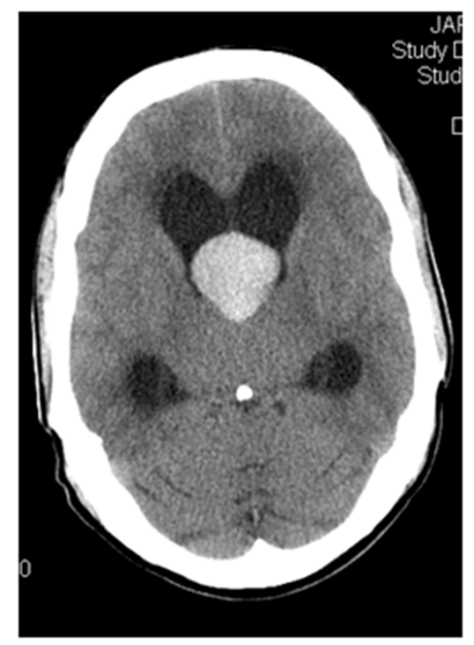

Figure 7 CT (Brother B) with colloid cyst and signs of hydrocephalus.

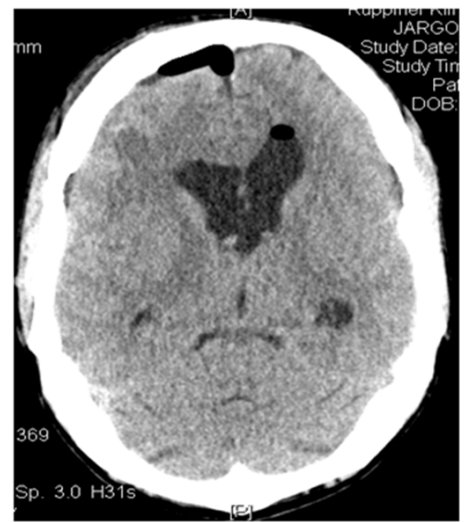

Figure $8 \mathrm{CT}$ (Brother B) Postoperative follow-up CT scan three days after surgery.

Treatment options include conservative, microsurgical, or endoscopic treatment. ${ }^{4,14,15}$ An asymptomatic patient may be managed with follow-up imaging studies. ${ }^{1}$ If neurological signs are seen, prompt imaging studies should be obtained and a timely microsurgical or endoscopic resection planned., ${ }^{4,14,15}$ In case of brother B, the rapid clinical deterioration has forced an emergency operation without performing further diagnosis. A further knowledge from this case is that, although brother B was admitted with wide pupils and without brainstem reflexes, the timely operation allowed a prompt weaning, and the patients presented no neurological losses. The slightly attentional impairments should be observed in the long time followup. According to these findings, a genetic origin of colloid cysts can be supposed. Further genetic studies are needed to confirm these observations.

\section{Acknowledgments}

None.

\section{Conflicts of interest}

None.

\section{Funding}

None.

\section{References}

1. Beaumont TL, Limbrick DD Jr, Rich KM, et al. Natural history of colloid cysts of the third ventricle. J Neurosurg. 2016;125(6):1420-1430.

2. Wallmann H. Eine Colloidcyste im dritten Hirnventrikel und ein Lipom im Plexus choroideus. Virchows Arch Pathol Anat. 1858;14:385.

3. Pollock BE, Schreiner SA, Huston J. A theory on the natural history of colloid cysts of the third ventricle. Neurosurg. 2000;46(5):1077-1081.

4. Sheikh AB, Mendelson ZS, Liu JK. Endoscopic versus microsurgical resection of colloid cysts: a systematic review and meta-analysis of 1,278 patients. World Neurosurg. 2014;82(6):1187-1197.

5. Kapu R, Symss NP, Pande A, et al. Management of pediatric colloid cysts of anterior third ventricle: A review of five cases. $J$ Pediatr Neurosci. 2012;7(2):90-95.

6. Hamlat A, Casallo-Quiliano C, Saikali S, et al. Huge colloid cyst: Case report and review of unusual forms. Acta Neurochir. 2004;146(4):397-401

7. Joshi SM, Gnanalingham KK, Mohaghegh P, et al. A case of familial third ventricular colloid cyst. Emerg Med J. 2005;22(12):909-910.

8. Stoodley MA, Nguyen TP, Robbins P. Familial fatal and near-fatal third ventricle colloid cysts. Aust NZ J Surg. 1999;69(10):733-736.

9. Partington MW, Bookalil AJ. Familial colloid cysts of the third ventricle. Clin Genet. 2004;66(5):473-475.

10. Ronne-Engström E, Popek E. Symptomatic colloid cysts in the third ventricle of monozygotic twins. Ups J Med Sci. 2015;120(1):59-62.

11. Ibrahim AW, Farag H, Naguib M, et al. Neuroepithelial (colloid) cyst of the third ventricle in identical twins. J Neurosurg. 1986;65(3):401-403.

12. Ahmed SK, Stanworth PA. Colloid cysts of the third ventricle in identical twins. Br J Neurosurg . 2002;16(3):303-307.

13. Romani R, Niemela M, Korja M, et al. Dizygotic twins with a colloid cyst of the third ventricle: case report. Neurosurgery. 2008;63:E1003.

14. Solaroglu I, Beskonakli E, Kaptanoglu E, et al. Transcorticaltransventricular approach in colloid cysts of the third ventricle: surgical experience with 26 cases. Neurosurg Rev. 2004;27(2):89-92.

15. Apuzzo ML, Chikovani OK, Gott PS, et al. Transcallosal, interfornicial approaches for lesions affecting the third ventricle: surgical considerations and consequences. Neurosurgery. 1982;10: 547-554. 